\title{
A randomized trial of preoperative oral carbohydrates in abdominal surgery
}

\author{
Fatos Sada ${ }^{1 *}$, Avdyl Krasniqi², Astrit Hamza², Agreta Gecaj-Gashi', Besnik Bicaj ${ }^{2}$ and Floren Kavaja²
}

\begin{abstract}
Background: Carbohydrate-rich liquid drinks (CRLDs) have been recommended to attenuate insulin resistance by shortening the preoperative fasting interval. The aim of our study the effect of preoperative oral administration of CRLDs on the well-being and clinical status of patients.

Methods: A randomized, double blind, prospective study of patients undergoing open colorectal operations (CR) and open cholecyctectomy $(\mathrm{CH})$ was conducted. Patients were divided into three groups: study, placebo, and control. Visual analogue scale (VAS) scores for seven parameters (thirst, hunger, anxiety, mouth dryness, nausea, weakness and sleep quality) were recorded and compared for two different time periods (up to $24 \mathrm{~h}$ postoperatively and from 36 to $48 \mathrm{~h}$ postoperatively). The Simplified Acute Physiology Score changes (SAPS)-II between the three groups were also studied.

Results: There were 142 patients American Society of Anesthesiology (ASA) I or II enrolled in the study (CR = 71 and $\mathrm{CH}=71$ ). There were no significant differences in postoperative SAPS-II scores or lengths of hospital stay (LOS) between the groups. However, in CR patients, the degree of thirst was partially improved by drinking CRLDs $(P=0.027)$. In $\mathrm{CH}$ patients, on the other hand, feelings of thirst, hunger, mouth dryness, nausea and weakness showed significant improvement $(P<0.05)$.

Conclusion: Oral administration of carbohydrate-rich liquid drinks (CRLDs) improves the well-being in patients undergoing $\mathrm{CH}$, but the effect is less evident in patients undergoing $\mathrm{CR}$. No significant improvements were seen in clinical status or in length of hospital stay in either group.
\end{abstract}

Trial registration: ANZCTR.org.au: ACTRN12614000995673 (registered on 16/09/2014).

Keywords: Carbohydrates, Fasting, Thirst, Preoperative use of carbohydrates, Postoperative period

\section{Background}

Insulin resistance, as a stress inducer, is a positive protective reaction against surgery [1]. As a response to injury (surgery), activation of neuroendocrine and inflammation systems occurs as a protective reaction that initiates insulin resistance [2,3]. However, beyond a point, this resistance begins to have negative consequences for patient health $[4,5]$. One of the mechanisms to attenuate insulin resistance is preoperative administration of carbohydrate-rich liquid drinks (CRLDs) [6].

The more complex or lengthy the surgery, (i.e., the severity: tissue trauma, blood loss), the more severe the

\footnotetext{
* Correspondence: fatossada@hotmail.com

${ }^{1}$ Clinic of Anesthesiology and Intensive Care, University Clinical Center of Kosovo, Rr. Hyzri Talla, hy 7/8, Bregu i Diellit, Zona e Lindjes, Prishtina, Kosovo Full list of author information is available at the end of the article
}

development of insulin resistance [7]. In cholecystectomy procedures, insulin sensitivity was reduced by $56 \%$ in one study $(\mathrm{P}<0.01)[8]$ while in major colorectal surgery interventions, insulin sensitivity can be reduced as much as $90 \%$ [1].

The nothing by mouth rule (NPO) from the night before surgery, which extends throughout the postoperative period (can last 12-16 h), in recent years, has been under scrutiny [9-11]. Studies have revealed that fasting can intensify perioperative insulin resistance $[12,13]$. Administration of an iso-osmolar, carbohydrate rich, beverage preoperatively is the most efficient and natural way to provide certain quantities of carbohydrates and does not pose any threat from vomiting or aspiration if taken no sooner than $2 \mathrm{~h}$ before anesthesia induction [14-16]. As a result

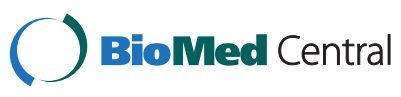

(c) 2014 Sada et al.; licensee BioMed Central Ltd. This is an Open Access article distributed under the terms of the Creative Commons Attribution License (http://creativecommons.org/licenses/by/2.0), which permits unrestricted use, distribution, and reproduction in any medium, provided the original work is properly credited. The Creative Commons Public Domain Dedication waiver (http://creativecommons.org/publicdomain/zero/1.0/) applies to the data made available in this article, unless otherwise stated. 
of these studies, CRLDs are recommended to minimize preoperative fasting $[17,18]$.

It has been reported also that preoperative consumption of CRLDs reduces patient discomfort and anxiety in the perioperative period, [19] and resulted in a shorter hospital stay [20]. In many countries, preoperative administration of carbohydrates is included in the institutional protocols [21-23], although this is not wide spread practice. These recommendations rely on studies that have suggested that administration of carbohydrates reduces metabolic stress, insulin resistance and attenuates the nitrogen losses, [24] as well as improving muscular strength in larger groups [25].

We designed the study to assess whether preoperative oral administration of CRLDs has an impact on patient well-being, clinical status, time to regain activities of daily living, and reduction in the length of hospital stay, in patients undergoing open abdominal surgery $(\mathrm{CR}, \mathrm{CH})$.

\section{Methods}

This prospective, double-blind, randomized trial was performed between January 2010-January 2012 at the University Clinical Center of Kosovo. Patients were randomized into one of three groups: a study group, placebo, and control. In this study, the placebo beverage was indistinguishable in appearance and taste as possible from the special formula. For this purpose, a colleague blinded to the rest of the study (patients, clinical and biochemical parameters recorded during the study) was asked to prepare and label beverages according to the randomization codes. All other researchers were blinded to those codes. The study group received $800 \mathrm{~mL}$ (per os) of carbohydrate beverage in the evening before surgery (22:00) and an additional $400 \mathrm{~mL} 2 \mathrm{~h}$ before anesthesia induction. The placebo group received a non-caloric colorless liquid with the same taste and without carbohydrates in the same amount as the patients in the study group. The control group did not receive any of these drinks and were subject to the traditional preoperative fasting. Each procedure was performed following the written consent obtained from each patient. Inclusion criteria were that patients were older than 18 years, undergoing an operation of the colon and rectum for benign and malignant diseases, or open abdominal cholecystectomy for chronic cholecystitis. Each group of patient was analyzed and reported separately. Exclusion criteria were type 1 or 2 diabetes mellitus, stomach emptying disorders or documented gastric esophageal reflex disease, emergency surgery interventions, or refusal of the patient to participate in the trial. The Ethics Committee of the Medical Faculty/ University of Pristina approved the trial (protocol number: 2128, date 31.05.2010).
All beverages were packed into identical bottles marked with numbers (containing carbohydrates or placebo) by an assigned person who did not provide the liquids to the patients and did not take part in the evaluation of the results. For the study group, the beverage contained $12.5 \%$ carbohydrates, $50 \mathrm{kcal} / 100 \mathrm{~mL}, 285 \mathrm{mOsmol} / \mathrm{kg}$ (NutriciapreOp, Nutricia Ltd., Wiltshire, UK, who provided the supplements.). Patients were premedicated in the evening before the surgery with $5 \mathrm{mg}$ intramuscular diazepam and $0.3 \mathrm{ml}$ subcutaneous Fraxiparine (Nadoparin, GlaxoSmithKline, UK). Patients were asked to have a regular diet for at least two days prior to admission to the clinical ward. To achieve standardization across the participating departments, patients had a bowel preparation with a $2 \times 45 \mathrm{ml}$ dose of sodium phosphate given orally the day before surgery (at 1500 and 2000). Intraoperative fluid management was depended on the anesthetist's preference. The patient was administered prophylactic antibiotics 30 to 60 minute before the first incision (A first or second generation cephalosporin plus metranidazol given by i.v. route, single dose of each). No IV fluids were given to any of the groups preoperatively. Anesthesia induction was performed with intravenous midazolam $2 \mathrm{mg}$, fentanyl $(3-4 \mathrm{mcg} / \mathrm{kg}$ ) and thiopental $(4-6 \mathrm{mg} / \mathrm{kg})$. Pancuronium $(0.1 \mathrm{mg} / \mathrm{kg})$ or atracurium $(0.5 \mathrm{mg} / \mathrm{kg})$ was used for muscular relaxation. General anesthesia was maintained with continual propofol and intermittent bolus doses of fentanyl. Postoperative pain was treated with NSAID and tramadol hydrochloride, while for PONV there was not used any prophylactic drug.

\section{Endpoints \\ Primary endpoints}

Patient well-being Thirst, anxiety, hunger, mouth dryness, nausea, weakness and sleep quality were assessed using visual analogue scale (VAS) scores 1-10. [26] In order to have a clearer picture if $\mathrm{CHO}$ drinks do or not have an impact in postoperative well being of the patients VAS score questionnaire was filled twice, within $24 \mathrm{~h}$ following the surgery (in the morning of the first postoperative day) and between 36 to $48 \mathrm{~h}$ following the surgery (in the morning of the second postoperative day).

Patient clinical status Clinical evaluation by the Simplified Acute Physiology Score (SAPS-II), [27] was performed within $24 \mathrm{~h}$ following the surgery. Lowest or highest recorded BP and heart frequency following $24 \mathrm{~h}$ after surgery was used to calculate SAPS II score.

Length of hospital stay The length of hospital was recorded for each patient. 


\section{Secondary endpoint}

Convalescence Regaining daily activities.

Data are presented using tabular presentations. Data processing was performed using the statistical package InStat 3 (San Diego, California, USA). The following statistics were calculated: arithmetic mean, standard deviation, and standard error of the mean. Minimal and maximal values were also recorded. For statistical testing, we used one-way analysis of variance (ANOVA) and the Bonferroni test for multiple comparisons for parametric data and the Kruskal-Wallis (KW) test and the Dunn test for multiple comparisons for non-parametric data. Differences were significant for values of $\mathrm{P}<0.05$.

\section{Results}

There were 162 patients enrolled in the study, form which 142 were analyzed $(\mathrm{CR}=71$ and $\mathrm{CH}=71)$ (see Additional file 1 - CONSORT diagram). All patients were American Society of Anesthesiology (ASA) I or II. Characteristics of the study, placebo and control groups are presented for $\mathrm{CR}$ and $\mathrm{CH}$ patients in Tables 1 and 2. No statistically significant differences were found in mean ages between the three groups in CR patients $(\mathrm{F}=0.54$, $\mathrm{P}=0539, \mathrm{P}>0.05)$. No statistically significant differences in the mean duration of surgery between the CR study, placebo and control groups ( $\mathrm{KW}=0.96, \mathrm{P}>0.05)$. Also, between the groups of $\mathrm{CH}$ patients no difference was noted for demographic data (age $\mathrm{F}=0.75, \mathrm{P}>0.05$ ). The results of VAS score comparisons for seven parameters, 0-24 $\mathrm{h}$ and 36-48 h postoperatively, for both the CR and $\mathrm{CH}$ groups are presented in Table 3.

\section{Colorectal group}

For the six out of seven parameters of VAS scores (hunger, anxiety, mouth dryness, nausea, fatigue and sleep quality), we found no statistically significant differences between the groups, $0-24 \mathrm{~h}$ and 36-48 $\mathrm{h}$ after CR surgery ( $\mathrm{P}>0.05)$. Multiple comparisons gave the same results for these parameters (study group vs. placebo group, $\mathrm{P}>0.05$;

Table 1 Demographic and other clinical data for colorectal surgery patients- gender, age and surgery duration were identical among the three study groups

\begin{tabular}{cccc}
\hline & Study & Placebo & Control \\
\hline Gender & & & \\
$\mathrm{n}(\%)$ & $22(100)$ & $23(100)$ & $26(100)$ \\
M & $11(50)$ & $9(31.1)$ & $13(50)$ \\
F & $11(50)$ & $14(60.9)$ & $13(50)$ \\
Age (years) & & & \\
Mean & $57.9 \pm 12.0$ & $56.6 \pm 13.0$ & $53.8 \pm 15.8$ \\
Surgery duration (hours) & & & \\
Mean & $3.3 \pm 0.5$ & $3.1 \pm 0.4$ & $3.1 \pm 0.5$ \\
\hline
\end{tabular}

Table 2 Demographic and other clinical data for cholecystectomy patients- gender, age and surgery duration were identical among the three study groups

\begin{tabular}{cccc}
\hline & Study & Placebo & Control \\
\hline Gender & & & \\
$\mathrm{n}(\%)$ & $22(100)$ & $23(100)$ & $26(100)$ \\
$\mathrm{M}$ & $6(27)$ & $6(26)$ & $8(31)$ \\
$\mathrm{F}$ & $16(73)$ & $17(74)$ & $18(69)$ \\
Age (years) & & & \\
Mean & $55.8 \pm 13.5$ & $54.8 \pm 15.1$ & $59.1 \pm 12.0$ \\
Surgery duration (hours) & & & \\
Mean & $1.2 \pm 0.4$ & $1.2 \pm 0.3$ & $1.3 \pm 0.4$ \\
\hline
\end{tabular}

study group vs. control group, $\mathrm{P}>0.05$; placebo group vs. control group, $\mathrm{P}>0.05$ ).

During the first $24 \mathrm{~h}$ following the surgery, thirst was the only parameter statistically significant different between the placebo and control groups ( $K W=7.19$, $\mathrm{P}=0027$, i.e. $\mathrm{P}<0.05)$. During postoperative time interval between $36-48 \mathrm{~h}$, the only significant difference in thirst was between the study versus control group (Table 3 ). However, no significant statistical difference between the mean values of SAPS scores were found $(\mathrm{KW}=0.98$, $\mathrm{P}>0.05$ ) (Table 4). Multiple comparisons gave the same results (study group vs. placebo group, $\mathrm{P}>0.05$; study group vs. control group, $\mathrm{P}>0.05$; placebo group vs. control group, $\mathrm{P}>0.05$ ).

LOS for the study group was $10.0 \pm 3.4$ days, control group $10.1 \pm 4.7$ days, and placebo group $10.3 \pm 2.7$. There was no significant statistical difference in the LOS between the groups $(\mathrm{KW}=1.67, \mathrm{P}>0.05)$. We found no statistically significant differences in the time to return of bowel sounds, $t$ flatus, defecation, sitting out of bed, oral intake, walk with assistance, walk without assistance, or nasogastric drainage for the patients between the groups (KW, $\mathrm{P}>0.05$ ), (study group vs. placebo group, $\mathrm{P}>0.05$; study group vs. control group, $\mathrm{P}>0.05$; placebo group vs control group, $\mathrm{P}>0.05$ ).

\section{Cholecystectomy group $(\mathrm{CH})$}

There were statistically significant differences $(\mathrm{P}<0.05)$ in the degree of thirst, hunger, mouth dryness, nausea and weakness in the study group compared with the control group in less than $24 \mathrm{~h}$ following the surgery, while the differences in degree of anxiety and sleep quality were not significant $(\mathrm{P}>0.05$ ) (Table 3). However, 36-48 h following surgery, only mouth dryness was found to be significant, when comparing study group vs. control group $(\mathrm{P}<0.05)$. The degree of anxiety, nausea, weakness and sleep quality were not significant $(\mathrm{P}>0.05)$.

Comparing study group vs. placebo group, in two time intervals, lees then $24 \mathrm{~h}$ and $36-48 \mathrm{~h}$ there were no 


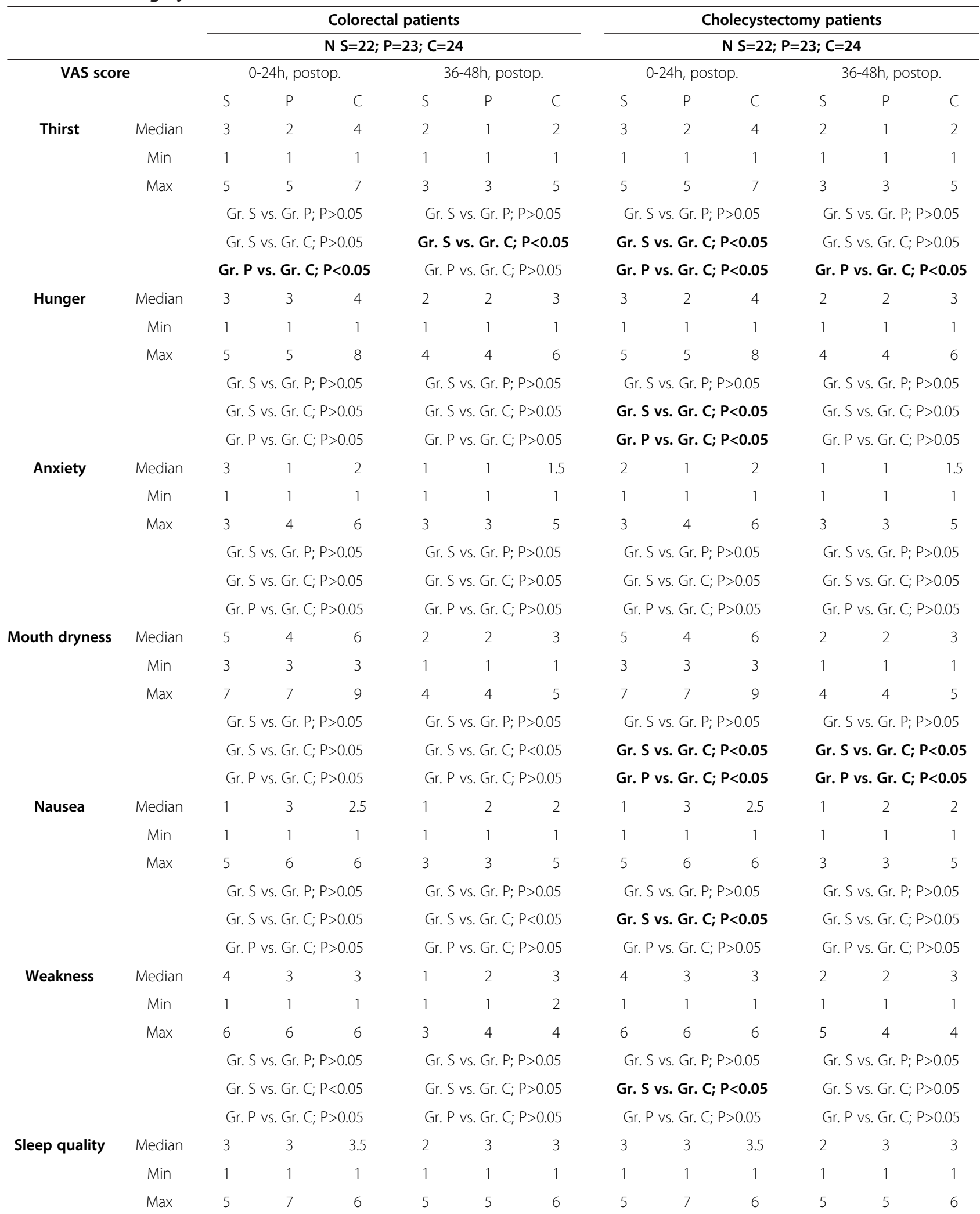


Table 3 Well-being by VAS score (Continued)

$\begin{array}{llll}\text { Gr. S vs. Gr. P; P>0.05 } & \text { Gr. S vs. Gr. P; P>0.05 } & \text { Gr. S vs. Gr. P; P>0.05 } & \text { Gr. S vs. Gr. P; P>0.05 } \\ \text { Gr. S vs. Gr. C; P>0.05 } & \text { Gr. S vs. Gr. C; P>0.05 } & \text { Gr. S vs. Gr. C; P>0.05 } & \text { Gr. S vs. Gr. C; P>0.05 } \\ \text { Gr. P vs. Gr. C; P>0.05 } & \text { Gr. P vs. Gr. C; P>0.05 } & \text { Gr. P vs. Gr. C; P>0.05 } & \text { Gr. P vs. Gr. C; P>0.05 }\end{array}$

For each evaluation statistic, the bold numbers denotes significant statistical difference.

significant differences in any of the seven well being parameters.

LOS for the study group was $4.4 \pm 0.8$ days, control group $4.4 \pm 1.0$ days, and placebo group $4.6 \pm 1.1$. There was no significant statistical difference in the LOS between the groups $(\mathrm{KW}=2.0, \mathrm{P}>0.05)$. In addition, the SAPS II score and recovery time were not statistically different between the groups (study group vs. placebo group; $\mathrm{P}>0.05$, study group vs. control group; $\mathrm{P}>0.05$, placebo group vs. control group; $\mathrm{P}>0.05$ ).

\section{Discussion}

We have attempted to answer the question if the postoperative well-being of the patients is improved by the preoperative administration of CRLDs. While, thirst was the only parameter that was improved in patients undergoing colorectal surgery, all other well-being parameters of VAS score were not affected. However, in patients undergoing open cholecystectomy, our data reveal that the postoperative well-being of patients who received CRLDs in the preoperative period improved five out of seven well-being parameters (thirst, hunger, mouth dryness, nausea and weakness) when compared the study group vs. control group, or for three parameters when compared the placebo group vs. control group $(\mathrm{P}<0.05)$.

Attenuated thirst and a reduced need for perioperative administration of inotropic drugs when taking CRLDs have been observed in patients undergoing open heart surgery interventions [28]. Hausel and colleagues, [14]

Table 4 The parameters of SAPS II score values by group in colorectal patients- clinical evaluation by SAPS-II was performed within $\mathbf{2 4} \mathrm{h}$ following the surgery

\begin{tabular}{cccc}
\hline SAPS II score & \multicolumn{1}{c}{ Study Gr. } & Placebo Gr. & Control Gr. \\
\hline Number of patients & 22 & 23 & 23 \\
Mean & 13.0 & 12.1 & 11.0 \\
SD & 6.5 & 6.6 & 7.8 \\
SEM & 1.39 & 1.37 & 1.62 \\
Min & 0 & 0 & 0 \\
Max & 29 & 23 & 32 \\
Kruskal Wallis test & & KW=0.98, P>0.05 \\
Dunn Multiple Comparisons Test & \multicolumn{3}{c}{ S. Gr. vs. P. Gr.; $P>0.05$} \\
& S. Gr. vs. C. Gr.; $P>0.05$ \\
& P. Gr. vs. C. Gr.; $P>0.05$
\end{tabular}

Gr. S: study group, Gr. P: placebo group, Gr. C: control group. utilizing VAS for patients categorized under ASA I-II undergoing abdominal surgery $(\mathrm{n}=252)$, found no differences between the groups ( $\mathrm{CHO}$ and placebo) in the degree of thirst, although there was a significant difference compared with the control group. However, in the same study it was reported that patients who received CRLDs experienced a significant reduction in anxiety and hunger.

In our study there was no difference in SAPS II score or length of hospital stay, and other clinical data were the same for both patients undergoing colorectal and cholecystectomy operations. In contrast to the results of this study, De Aguilar-Nascimento and colleagues conducted a study of 60 female patients undergoing cholecystectomy, patients with carbohydrates intake had reduced gastrointestinal discomfort (vomiting and abdominal distension), as well as a shorter hospital stay [29]. Furthermore, intake of these drinks, which reduces preoperative fasting, demonstrated positive effects on thirst, hunger, perioperative anxiety and muscular strength $[29,24]$. On the other hand, Henriksen and colleagues reported results from a small study $(\mathrm{n}=48)$ prior to elective bowel resection, in which their patients showed no differences, even for thirst [27]. In contrast our data, as reported elsewhere [30], show that thirst, as a main component in preoperative discomfort, is effectively reduced by the intake of clear liquids. In addition, in minor surgeries such is laparoscopic cholecystectomy, another study showed no differences in postoperative sleep or well-being, [31] while yet another study indicated less nausea and vomiting for the group with carbohydrate intake compared with fasting patients [32].

An important question arises from our study: why did the study group have greater improvement in patients undergoing cholecystectomy than those undergoing colorectal surgical interventions when taking CRLDs? Results varied between different patients population, investigating the same parameters. In both/different types of surgical operations on patients with varying postoperative insulin resistance the results have been inconsistent. In colorectal operations, which result in more insulin resistance, there were no significantly different results compared with cholecystectomy operations where well-being parameters were statistically different in a positive way for patients drinking a carbohydrate versus control group. Reason might be longer duration of operation in colorectal group where there was enough time to replace volume deficit 
that exists maybe in control group, so in postoperative period both groups were equally balanced with fluids. This didn't happen in cholecystectomy operations due to shorter length of operation. This is only an assumption since measuring IV volume loading during operation was not a part of this study. In this study, also majority of results when comparing study group vs. placebo group do not show any significant difference. There are other studies that do have similar results such as Mathur et al. were $\mathrm{CHO}$ treatment did not improve postoperative fatigue or length of hospital stay after major abdominal surgery, [33] or Hausael at al. found no differences between the groups (CHO and placebo) in the degree of thirst [14]. This might bring us to hypothesis that volume of oral fluids taken is more important than the energy that they posses based on carbohydrate concentration.

\section{Study limitations}

This study has its own limitations. It is limited by small sample size e.g. small number of patients per group. Approval from Ethical Committee for the study to last two years, limited the number of patients included in research.

Although previous authors $[1,7,8]$ talk about difference in insulin resistance in colorectal operations and in cholecystectomy operation, in our study we did not measure insulin resistance or insulin levels since it was not our aim. We measured glucose levels in blood pre and postoperatively as part of routine lab for this project.

\section{Conclusions}

Preoperative oral intake of carbohydrates yields different postoperative well-being (VAS) scores for patients undergoing different operations. The only positive effect on patients undergoing colorectal operations was an attenuation of thirst (36-48 h postoperatively). For patients undergoing cholecystectomy operations, the VAS score was significantly better in patients taking carbohydrate drinks for thirst, hunger, mouth dryness, nausea and weakness. Other aspects studied showed no significant differences among the study group, control group or the placebo group regardless of the type of operation, e.g. clinical status (SAPS-II score), patient convalescence and the length of hospital stay.

\section{Additional file}

Additional file 1: CONSORT Flow Diagram. Flow diagram of subject progress through the phase of a randomized trial.

\section{Competing interests}

The authors declare that they have no competing interests.

\section{Authors' contributions}

FS and AK have been involved in study conception and design. AGG and FS have been involved in acquisition of data. AGG, AH and FK have been involved in analyzing and interpreting the data. FS did drafting of the manuscript. FS, AK and $B B$ did the critical revision of the manuscript. $R L$ did a critical review of the final manuscript. All authors read and approved the final manuscript.

\section{Author's information}

FS is a specialist of Anesthesiology and Intensive Care and works at the University Clinical Center of Kosovo. FS is an Assistant Professor in Department of Anesthesiology and Surgery on Faculty of Medicine at the University of Pristina. He holds an MS degree, and is now working on a PhD doing clinical research on the benefits of preoperative usage of carbohydrate reach liquid drinks.

\section{Author details}

${ }^{1}$ Clinic of Anesthesiology and Intensive Care, University Clinical Center of Kosovo, Rr. Hyzri Talla, hy 7/8, Bregu i Diellit, Zona e Lindjes, Prishtina, Kosovo. ${ }^{2}$ Clinic of Surgery, University Clinical Center of Kosovo, Prishtina, Kosovo.

Received: 15 November 2013 Accepted: 24 September 2014 Published: 17 October 2014

\section{References}

1. Thorell A, Nygren J, Ljungqvist O: Insulin resistance: a marker of surgical stress. Curr Opin Clin Nutr Metab Care 1999, 2:69-78.

2. Kremen J, Dolinkova M, Krajickova J, Blaha J, Anderlova K, Lacinova Z, Haluzikova D, Bosanska L, Vokurka M, Svacina S, Haluzik M: Increased subcutaneous and epicardial adipose tissue production of proinflammatory cytokines in cardiac surgery patients: possible role in postoperative insulin resistance. J Clin Endocrinol Metab 2006, 91:4620-4627.

3. Soop M, Nygren J, Myrenfors $P$, Thorell A, Ljungqvist O: Preoperative oral carbohydrate treatment attenuates immediate postoperative insulin resistance. Am J Physiol Endocrinol Metab 2001, 280:E576-E583.

4. Thorell A, Efendic S, Gutniak M, Häggmark T, Ljungqvist O: Development of postoperative insulin resistance is associated with the magnitude of operation. Eur J Surg 1993, 159:593-599.

5. Svanfeldt M, Thorell A, Brismar K, Nygren J, Ljungqvist O: Effects of 3 days of "postoperative" low caloric feeding with or without bed rest on insulin sensitivity in healthy subjects. Clin Nutr 2003, 22:31-38.

6. Nygren J, Soop M, Thorell A, Efendic S, Nair KS, Ljungqvist O: Preoperative oral carbohydrate administration reduces postoperative insulin resistance. Clin Nutr 1998, 17:65-71.

7. Tsubo T, Kudo T, Matsuki A, Oyama T: Decreased glucose utilisation during prolonged anaesthesia and surgery. Can J Anaesth 1990, 37:645-649.

8. Thorell A, Nygren J, Essén P, Gutniak M, Loftenius A, Andersson B, Ljungqvist $\mathrm{O}$ : The metabolic response to cholecystectomy: insulin resistance after open compared with laparoscopic operation. Eur J Surg 1996, 162(3):7-91.

9. Maltby JR, Sutherland A, Sale GP, Shaffer EA: Preoperative oral fluids: Is afive-hour fast justified prior to elective surgery? Anesth Analg 1986, 65:1112-1116.

10. Strunin L: How long should patients fast before surgery. Time for new guidelines. Br J Anaesth 1993, 70:1-3.

11. Practice guidelines for preoperative fasting and the use of pharmacologic agents to reduce the risk of pulmonary aspiration: application to healthy patients undergoing elective procedures. Anesthesiology 2011, 114:495-511.

12. Nygren J, Thorell A, Brismar K, Karpe F, Ljungqvist O: Short-term hypocaloric nutrition but not bed rest decrease insulin sensitivity and IGF-I bioavailability in healthy subjects: the importance of glucagon. Nutrition 1997, 13:945-951.

13. Martinez-Riquelme AE, Allison SP: Insulin revisited. Clin Nutr 2003, 22(1):7-15.

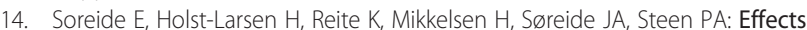
of giving water $20-450 \mathrm{ml}$ with oral diazepam premedication 1-2 $\mathrm{h}$ before operation. Br J Anaesth 1993, 71:503-506.

15. Nygren J, Thorell A, Jacobsson H, Larsson S, Schnell PO, Hylén L, Ljungqvist $\mathrm{O}$ : Preoperative gastric emptying. Effects of anxiety and oral carbohydrate administration. Ann Surg 1995, 222:728-734. 
16. Yagci G, Can MF, Ozturk E, Dag B, Ozgurtas T, Cosar A, Tufan T: Effects of preoperative carbohydrate loading on glucose metabolism and gastric contents in patients undergoing moderate surgery: a randomized, controlled trial. Nutrition 2008, 24:212-216.

17. Brady M, Kinn S, Stuart P: Preoperative fasting for adults to prevent perioperative complications. Cochrane Database Syst Rev 2003, 4, CD004423.

18. Ljungqvist O, Soreide E: Preoperative fasting. Br J Surg 2003, 90(4):400-406.

19. Hausel J, Nygren J, Lagerkranser M, Hellström PM, Hammarqvist F, Almström C, Lindh A, Thorell A, Ljungqvist O: A carbohydrate-rich drink reduces preoperative discomfort in elective surgery patients. Anesth Analg 2001, 93(5):1344-1350

20. Ljungqvist O, Nygren J, Thorell A, Brodin U, Efendic S: Preoperative nutrition-elective surgery in the fed or the overnight fasted state. Clin Nutr 2001, 20(Suppl 1):167-171.

21. Soreide E, Eriksson LI, Hirlekar G, Eriksson H, Henneberg SW, Sandin R, Raeder J: Pre-operative fasting guidelines: an update. Acta Anaesthesiol Scand 2005, 49(8):1041-1047.

22. Spies CD, Breuer JP, Gust R, Wichmann M, Adolph M, Senkal M, Kampa U, Weissauer W, Schleppers A, Soreide E, Martin E, Kaisers U, Falke KJ, Haas N, Kox WJ: Preoperative fasting. An update. Anaesthesist 2003, 52(11):1039-1045.

23. Soreide $E$, Ljungqvist $O$ : Modern preoperative fasting guidelines: a summary of the present recommendations and remaining questions. Best Pract Res Clin Anaesthesiol 2006, 20(3):483-491.

24. Svanfeldt M, Thorell A, Hausel J, Soop M, Rooyackers O, Nygren J, Ljungqvist O: Randomized clinical trial of the effect of preoperative oral carbohydrate treatment on postoperative whole-body protein and glucose kinetics. Br J Surg 2007, 94(11):1342-1350.

25. Henriksen MG, Hessov I, Dela F, Hansen HV, Haraldsted V, Rodt SA: Effects of preoperative oral carbohydrates and peptides on postoperative endocrine response, mobilization, nutrition and muscle function in abdominal surgery. Acta Anaesthesiol Scand 2003, 47(2):191-199.

26. Gift AG: Visual analogue scales: measurement of subjective phenomena. Nurs Res 1989, 38(5):286-288.

27. Le Gall JR, Lemeshow S, Saulnier F: A new Simplified Acute Physiology Score (SAPS II) based on a European/North American multicenter study. JAMA 1993, 270(24):2957-2963.

28. Breuer JP, von Dossow V, von Heymann C, Griesbach M, von Schickfus M, Mackh E, Hacker C, Elgeti U, Konertz W, Wernecke KD, Spies CD: Preoperative oral carbohydrate administration to ASA III-IV patients undergoing elective cardiac surgery. Anesth Analg 2006, 103:1099-1108.

29. de Aguilar-Nascimento JE, Dock-Nascimento DB, Faria MSM, Maria EV, Yonamine F, Silva MR, Adler T: Ingestãopré-operatória de carboidratosdiminui a ocorrência de sintomasgastrointestinaispós-operatóriosempacientessubmetidos à colecistectomia. ABCD Arq Bras Cir Dig 2007, 20:77-80.

30. Madsen M, Brosnan J, Nagy VT: Perioperative thirst: a patient perspective. $J$ Perianesth Nurs 1998, 13:225-228.

31. Bisgaard T, Kristiansen VB, Hjortsø NC, Jacobsen LS, Rosenberg J, Kehlet H: Randomized clinical trial comparing an oral carbohydrate beverage with placebo before laparoscopic cholecystectomy. Br J Surg 2004, 91(2):151-158.

32. Hausel J, Nygren J, Almström C: Preoperative oral carbohydrates improves well being after elective colorectal surgery. Clin Nutr 1999, 18(suppl. 1):80.

33. Mathur S, Plank LD, McCall JL, Shapkov P, Mcllroy K, Gillanders LK, Merrie AE, Torrie JJ, Pugh F, Koea JB, Bissett IP, Parry BR: Randomized controlled trial of preoperative oral carbohydrate treatment in major abdominal surgery. Br J Surg 2010, 97:485-494.

doi:10.1186/1471-2253-14-93

Cite this article as: Sada et al:: A randomized trial of preoperative oral carbohydrates in abdominal surgery. BMC Anesthesiology 2014 14:93.

\section{Submit your next manuscript to BioMed Central and take full advantage of:}

- Convenient online submission

- Thorough peer review

- No space constraints or color figure charges

- Immediate publication on acceptance

- Inclusion in PubMed, CAS, Scopus and Google Scholar

- Research which is freely available for redistribution

Submit your manuscript at www.biomedcentral.com/submit
Ciomed Central 